\title{
Mediatizaciones en los subtes de Buenos Aires Arte mural, comunicación y espacio urbano ${ }^{1}$
}

\section{BEATRIZ SZNAIDER}

bsznaider@gmail.com - Universidad Nacional de Buenos Aires (UBA), Argentina

Fecha de recepción: 20 de abril de 2017

Fecha de aceptación: 10 de mayo de 2017

\section{RESUMEN}

Durante los años '30, en la ciudad de Buenos Aires, el arte mural marcó un hito urbano al homenajear la expansión del subte a través de lo que Belej (2012) llamó un verdadero "programa iconográfico". En las décadas posteriores primaron intervenciones de carácter más acotado y recién a partir de 1998 aumentó de manera exponencial la producción de murales. En los últimos años, además, creció y se renovó casi toda la comunicación visual (señalética, cartelería comercial y mobiliario). En conjunto con las producciones artísticas, configuran un sistema complejo con el que el usuario del subte toma contacto desde una posición interactiva, en el sentido de que demanda algún tipo de acción kinésica, perceptiva y cognitiva para su captura y, por lo tanto, supone distintas prácticas sociales.

En este trabajo recorreremos, de manera exploratoria, algunas novedades que surgen a partir de la expansión de las formas de intervención artística y comunicacional en los espacios del subte de Buenos Aires durante la última década. El objetivo es postular diversas hipótesis acerca del espacio público construido, del lugar de la institución que enuncia y del sujeto convocado, con especial atención en los vínculos entre arte público y comunicación, entre ciudad a cielo abierto y ciudad subterránea y entre usuario en broadcasting y usuario en networking.

PALABRAS CLAVE: arte mural, espacio urbano, mediatizaciones, comunicación.

\begin{abstract}
Duringthe 30s, in Buenos Airescity, themuralartmarked an urbanlandmark, whenhonored the expansion of the subway through what Belej (2012) called a true iconographic program. In the following decades interventions of a morelimited character prevailed and only since 1998 the production of murals increased exponentially. In recent years, in addition, almost all visual communication (signage, commercial posters and furniture) grew and renewed. Together with the artistic productions, they forma complex system with which the subway user takes contact from an interactive position, in the sense that it demands some kind kinesic, perceptive and cognitiveaction for its capture and, therefore, suppose different social practices.

In this work, we will expose, in an exploratory way, some new developments that arise from the expansion of the forms of artistic and communicational intervention in the subway spaces of Buenos Aires during the last decade. The objective is to postulate different hypotheses about the public constructed space, the place of theinstitution that enunciates and the summoned subject, with special attention in the links between public art and communication, between open sky city and underground city and between user in broadcasting and user in networking.

KEY WORDS: mural art, urban space, mediatizations, communication.

1 Esta investigación se inscribe dentro del proyecto financiado por la Universidad de Buenos Aires (UBA), Argentina. Facultad de Ciencias Sociales. Carrera de Ciencias de la Comunicación, UBACyT Dir.: JoséL. Fernández. "Letra, imagen, sonido. Convergencias y divergencias en los medios y en el espacio urbano", (2014-2017). 


\section{INTRODUCCIÓN}

En este trabajo vamos a poner foco en los espacios comunes del subte de Buenos Aires, lo que Eliseo Verón (2013) denominó "espacios conectivosinternos" (2013, p. 354), y en la relación entre murales y comunicación, por lo que nos concentraremos en los ámbitos extra-vagón. Propósito que, en su recorrido, permite además que homenajeemos a Verón y a Marc Augé, autores singulares en los estudios semióticos y antropológicos de los espacios del subterráneo, de sus trayectos, de sus comunicaciones, de la relación con la ciudad; quienes actualizaron sus primeras producciones, de 1983 y 1986 respectivamente, casi veinte años después. El gesto deja ver la necesidad de capturar las transformaciones que ocurrieron en esos espacios, en el pasaje que va de un siglo a otro, cuando se consolidaron nuevas formas de mediatización, especialmente a partir de las posibilidades que brindan las redes de telefonía móvil y de wifi.

Más atento, en el caso de Augé (2010), a sus propias sensaciones y a su lugar como observador, presenta en primera persona los desdoblamientos del etnólogo para mirar y mirarse en el devenir de su tiempo e interrogarse sobre el sentido de lo contemporáneo. No pierde de vista la novedad de la tecnología y se interroga sobre cuál sería el ambiente sonoro del vagón de subte si decenas de jóvenes melómanos abandonaran sus auriculares para compartir sus emociones musicales. Se responderá desdela distancia metodológica quele impone su condición de investigador pero también, reconocerála existencia de una brecha generacional que le impide entender ese mundo joven. Podemos captar las previsiones de Augé y aunque no sea su pregunta de base, creemos que alguna investigación empírica depararía sorpresas acerca de qué es lo que vive en ese "extremo del contacto del individuo con un sistema de intercambio mediático de amplia extensión cultural" que recibe a través del uso de auriculares en sus oídos: sea radio, música, música a través de la radio o de distintas plataformas de música en streaming (Fernández, 2016a).

La investigación original de Verón partió de una demanda institucional de la RAPT ${ }^{2}$ que buscaba conocer las expectativas de los usuarios, en el marco de un proyecto modernizador de la empresa que incluyó la fibra óptica en toda la red y que iba a transformar la "lógica comunicacional en lógica de marca" (2013, p. 336). Se pasa de la descripción de un territorio en el que funciona un sistema de transporte, a una territorialidad en la que se superponen no sólo redes multimedio de transporte, sino verdaderas redes de comunicación.

El interés de su perspectiva es que le permite constituir tipologías de espacios (que "produce" la institución) y de recorridos/apropiaciones (que genera el pasajero en situación de "reconocimiento" o en su "propia producción del viaje”) (p. 236). En la actualización de la investigación de 1983, que es teórica,

2 RAPT (Régie Autonome des Transports Parisiens), hoy Grupo RATP, quinto operador mundial de transporte público multimodal (Metro, tren, tranvía y autobús), dependiente del Estado francés. Consultado por última vez el 15 de marzo de 2017. En línea: www.ratp.fr/ 
Verón introduce lo que llama la emergencia de la “"persona ampliada': cuerpo + equipamiento inteligente" (p. 358) y trae de Amar (2011) sus preocupaciones acerca de una movilidad "religada", sustentable, creativa, que incorpore la "inteligencia masivamente paralela del conjunto de los pasajeros" (p. 98).

Nuestro análisis no avanza en un estudio sobre los usuarios concretos del subte, pero creemos que puede dejar un conjunto de observaciones válidas para futuras actividades de investigación etnográfica y socio-semiótica. Allí, la mirada de Augé y la propuesta de Verón pueden resultar estimulantes y en el caso de este último, además, organizadoras.

\section{UN BREVE CONTEXTO POLÍTICO-TÉCNICO SOBRE EL SUBTE PORTEÑO}

Los actores públicos y privados responsables del funcionamiento de la Red de Subtes son Subterráneos de Buenos Aires Sociedad del Estado (SBASE) y METROVÍAS, una unidad de negocios de transporte del grupo Roggio, una de las empresas de infraestructura y de servicios más importantes dela Argentina. A pesar de ser SBASE y METROVÍAS dos actores diferenciados que intervienen directamente en la operatoria del subte porteño, desde el punto de vista de la opinión pública, la responsabilidad de ambas empresas tiende a quedar subsumida en el lugar del Gobierno de la Ciudad, quien asume ese posicionamiento con los riesgos y beneficios de ser "la cara del servicio". Asociamos esta situación a históricas pujas interjurisdiccionales y a los complejos vínculos entre actores públicos y privados.

Hasta 1963 el Subte era operado por el Gobierno Nacional; ese año se crea SBASE que es transferida a la Ciudad en 1977. En 1993 se convierte en la primera red del mundo en ser concesionada a una empresa privada. En 2012, por ley nacional, se redefinen las competencias de SBASE y de METROVÍAS y, entre otros cambios, se establece la estatización de la explotación de los ingresos no tarifarios como la publicidad, locales comerciales y fibra óptica, cuando la gestión comercial en manos de METROVÍAS ya había sido objeto de distintas denuncias ${ }^{3}$. Recién en 2013 se realiza el traspaso del Subte a las autoridades locales, una deuda con la autonomía de la Ciudad que había sido sancionada constitucionalmente en 1996.

Importa la observación porque lo que tiende a disolverse es la competencia político-técnica de los actores concretos y las tensiones que devienen de su carácter público o privado. En términos de comunicación, se trata de desfasajes entre lo que son, lo que hacen, lo que dicen que hacen y lo que proyectan los actores implicados, lo que tendrá consecuencias importantes en términos de imagen pública de las instituciones.

La red de subterráneos porteña está compuesta actualmente por seis líneas:

3 Gentili R. (2012): “Negocio subterráneo: deficiencias en la regulación de Metrovías S.A.” y "En todo está Roggio: negocios colaterales en Metrovías S.A." (2012). Informes de Despacho, Diputado de la Ciudad Rafael Gentili MC (2009-2013).Disponibles en:rafagentili.com.ar/sitio/tag/subte-de-buenos-aires/Consultadosel 15demarzode2017. 
la "A", fundada en 1913 y la primera que se construyó en toda América Latina; la "B", de 1930; las líneas "C", "D" y "E", de 1933; el Premetro, que circula a nivel es de 1987 y la línea " $H$ " se inauguró en 2007. Los intervalos temporales marcan la pérdida del impulso innovador que caracterizó a la Ciudad; la Red tiene alrededor de $50 \mathrm{~km}$ bajo tierra y 7,5 km de extensión en superficie y une casi 100 estaciones ${ }^{4}$.

Desde 2006 la ciudad de Buenos Aires es gobernada por la fuerza política PRO (Propuesta Republicana) cuyo máximo referente es el ingeniero Mauricio Macri. Fuejefe de Gobierno dela Ciudad Autónoma deBuenos Aires(GCABA) durante dos mandatos, hasta que en 2015 fue electo Presidente de la Nación. Su sucesor en la Ciudad es Horacio Rodríguez Larreta, también perteneciente al partido PRO. Aunque aparecen algunos cambios en la comunicación del gobierno de Larreta, existe una unidad conceptual que justifica que en este trabajo se analice la comunicación del PRO en la ciudad como un todo.

Una de las principales promesas de campaña de Macri en su primer mandato había sido la de "construir $10 \mathrm{~km}$ de subte por año", promedio que alcanzó finalmente en sus ocho años de gestión. En cambio, con relación al transporte, se fomentó la peatonalización del microcentro y de zonas comerciales de la ciudad, se construyó una importante red de ciclovías y se instaló un sistema público de bicicletas. A partir de 2010 se comenzaron a implementar carriles exclusivos para colectivos bajo la marca "Metrobus"; hoy existen siete corredores operativos de carriles exclusivos para transporte públicos y uno más en construcción y se está extendiendo el sistema a otras jurisdicciones del país. Más allá de su eficacia, el "Metrobus" aparece como una solución compensatoria respecto de la promesa incumplida de $l o s$ " $10 \mathrm{~km}$..." y se puede asociar a estrategias de marketing territorial. Estos es, acciones comunicacionales que jerarquizan la infraestructura de superficie como una forma de lo inmediato y lo cosmético (Sznaider, 2013).

\section{PERSPECTIVA TEÓRICO-METODOLÓGICA, O CÓMO ESTUDIANMOS LAS MEDIATIZACIONES}

Nuestra marco de referencia macro es la ciudad, a la que entendemos como un ámbito complejo, múltiple y "hojaldrado" (Barthes, 1987) donde se pone en juego la relación de sus habitantes con el espacio urbano, con los otros y con las instituciones, y a la que accedemos analíticamente a partir de concebirla como "texto" (Barthes, 1993). Pero nuestro nivel de observación de ese espacio urbano será micro, donde se detectan en superficielas novedades y los cambios: analizaremos los entrejuegos significantes que se generan en los espacios comunes del subte y las mediatizaciones que lo configuran, para resituarlas otra vez en conclusiones medium y macro sobre la "ciudad construida".

4 Para contrastar, Santiago de Chile empezó la construcción del subterráneo en 1969 y hoy tiene más de $100 \mathrm{~km}$. 
Las perspectivas macro, medium y micro atienden aproximadamente a lo universal, a lo general y a lo particular. En lo macro aparecen objetos complejos, totalizantes, abstractos, teóricos. En lo medium es posible observar escenas de intercambio que abarcan fenómenos extensos, pero objetivables. Y en lo micro reconocemos productos, casos, prácticas situadas, acontecimientos, singularidades. Esta perspectiva permite replantear todos los fenómenos sociales e incorporarles nuevas inteligibilidades, sin caer en proyecciones deterministas de nociones y modos de funcionamiento que pertenecen a distintos niveles de lo social (Fernández, 2012, pp. 30-32).

Nos acercamos a las manifestaciones artísticas y comunicacionales en el espacio del subte a partir de categorías que provienen de un "esquema de construcción de la novedad mediática” (Fernández, 2008, p. 33), un tipo de ordenamiento descriptivo que permite diferenciar el conjunto de elementos presentes en la vida de todos los fenómenos mediatizados. Esa mediatización puede ser entendida como el proceso de transformación que se genera sobrelas materialidades significantes a partir de la presencia de ciertos dispositivos técnicos, cuando se producen intercambios discursivos genérico-estilísticos que se practican en la vida social y que tiene efectos particulares sobre la sociedad en cada época y que, a la vez, definen esa época (Fernández, 2008; Verón, 2013).

La mediatización no es un fenómeno de la actualidad, sino que conocemos distintas culturas extinguidas porque mediatizaron de alguna manera sus experiencias y sus prácticas. La pintura rupestre es un antecedente interesante respecto de nuestro caso ya que puede considerarse, además de una de las manifestaciones de arte mural más antiguas de las que la humanidad tiene conocimiento, como una de las primeras formas de mediatización, cualquiera sea el sentido que se le otorgue (comunicacional, didáctico, mágico, expresivo o ritual).

Respecto del dispositivo-técnico (DT), es una categoría muy importante en la perspectiva sociosemiótica desde la que trabajamos, aunque aparecen diferencias conceptuales entre autores del mismo campo ${ }^{5}$. El DT no se refiere directamente al soporte, ni a las tecnologías; es una configuración que se define a partir del trabajo físico de esas tecnologías sobre el soporte material y de sus resultados: centralmente, delas variaciones espacio-temporales que se generan y de sus consecuencias significantes.

Los géneros y estilos nos permiten entender las formaciones discursivas y establecer hipótesis a partir de su condición ordenadora: clasifican textos que se estructuran socialmente y que anteceden a las clasificaciones teóricas y permiten su diferenciación en distinto tipo de dispositivos para consensuarlos

5 Esas diferencias conceptuales también incluyen la definición de cuáles son las series que componen el fenómeno mediático. Véase en Fernández (2017) “Las mediatizaciones y su materialidad: revisiones", en el Cuaderno del $\mathrm{CIM} \mathrm{N}^{\circ} \mathrm{V}$. $\mathrm{I}^{\circ} \mathrm{COLOQUIO}$ INTERNO del CIM (Centro de Investigaciones en Mediatizaciones). «Conversatorio sobre investigaciones en curso", 18 de agosto de 2016. Rosario, Facultad de Ciencia Política y RR.II., Universidad Nacional de Rosario (UNR), Argentina. 
o "para evaluarlos y jerarquizarlos" (Fernández, 2008, p. 50). Desde el estilo como "modo de hacer", además, es posible reconstruir las "condiciones de unidad de objetos o comportamientos" y a partir de allí, focalizar en las relaciones entre "cambio histórico y carácter original de cada momento de producción discursiva” (Steimberg, 2013, pp. 60-68). Finalmente describimos la serie de las prácticas sociales por la relación de los sujetos con distintos dispositivos y discursividades.

En las trayectorias que se realizan dentro del subte reconocemos prácticas sociales particulares; tenemos en cuenta el conjunto de accesibilidades puestas en juego en toda escena de intercambio, activadas por distintos procesamientos espectatoriales: de mirada, de lectura, de intercambio, de escucha (Fernández, 2008), que en parte se buscan y en parte se encuentran. El tipo de acción que se moviliza en el espacio urbano resulta de una posición oscilante y de una atención flotante del sujeto; es lo que Fernández (2017) describe como una selección que se realiza más o menos conscientemente, entre los múltiples textos o imágenes con los que es posible encontrarse en la vía pública, donde se privilegia quévery qué recordar de entre todo el conjunto de estímulos. Muchas veces, inclusive, esa condición expectante no permita retener ningún tipo de información.

En esa línea, tenemos en cuenta algunos enfoques que provienen del interaccionismo simbólico y que nos permiten pensar el contacto de los usuarios del subte de Buenos Aires con sus murales y su comunicación, como inscriptos dentro de un flujo de actuaciones que se juegan en el día a día de la vida de los habitantes de la ciudad; como un "ritual menor" no determinado por las estructuras sociales, sino que "simplemente ayudan a elegir entre un repertorio disponible" que nos es "inaccesible" (Goffman, 1991, pp. 192-193).

Se puede hablar de una práctica "intersticial", como lo formula Igarza (2009) respecto de las formas de implicación y desempeño que habilitan las nuevas tecnologías digitales, pero que en nuestro caso también incluyen prácticas tradicionales o en broadcasting. En los fragmentos y "micropausas" de las actividades y movimientos, $\mathrm{o}$ a veces forzándolas, se comparten intercambios en networking con prácticas de escucha y de lectura tradicionales, en una posición interaccional; esto en (relativa) oposición a otra espectatorial, propia de la comunicación en broadcasting y que implica que los receptores tienen un lugar fijo y estable desde donde toman contacto con la emisión de su mediatización elegida y/o aceptada (Fernández, 2015;2016b).

Decimos en "relativa" oposición porque antes de la emergencia de los medios digitales e interactivos, en los medios de sonido (fonográficos y radiofónicos) y en la gráfica de vía pública, aparecían prácticas de consumo complejas de "capturar", "híbridas", más cercanas a las formas intersticiales del networking. Mientras que la posición interactiva, "estar en Facebook" o "escuchar radio en podcasting", como ya dijimos, no descarta momentos de intercambio en 
broadcasting como ver un spot publicitario, leer una noticia o escuchar una canción, aunque se trate de mediatizaciones de distinta "categoría" y a las que hay que reconstruir en su sistema. De todas maneras, estas observaciones nos permiten resituar lo viejo y lo nuevo y establecer continuidades y rupturas en los procesos de mediatización (Fernández, 2012; 2017).

En los espacios comunes del subte también se ejercen prácticas sociales no mediáticas, como adquirir el diario o una golosina en uno de sus kioscos. Y aunque más restringidamente, en algunos sectores de distribución o en los túneles de algunas estaciones también se puede beber o comer algo sentados en una barra, hacer operaciones bancarias - que no son mediáticas pero símediatizadas, porque se realizan a través de un procedimiento técnico que reemplaza el contacto cara a cara- y acceder a distintos servicios o rubros comerciales. Inclusive es posible que algunas personas ingresen al subte exclusivamente para realizar un trámite o compra; y aunque se trata de prácticas secundarias, podemos pensarlas como extensiones bajo tierra de la vida de todo ser urbano.

\section{LA COMUNICACIÓN VISUAL}

La nueva señalética institucional del Subte de Buenos Aires se comienza a desarrollar en 1995, a cargo de Ronald Shakespear y su Estudio, con rediseños en 2006, 2013 y $2015^{6}$. El mismo Shakespear, junto con Guillermo González Ruiz, había sido responsable del Primer Sistema de Identificación Visual y de Señales Urbanas de la Ciudad de Buenos Aires en 1972; un plan integral que sólo alcanzó al Subte en superficie, pero que por su carácter abarcativo y su fuerza utópica, al plantearse como una estrategia "transformadora" del espacio urbano a partir de una "política sígnica", constituye un intertexto fundacional desde el que leer los alcances y los límites de las intervenciones posteriores ${ }^{7}$.

6 La reconstrucción histórica es incompleta y sólo busca señalar los momentos más importantes del proceso. Ver Diseño Shakespear (shakespearweb.com/portfolio/subte). Consultado el 7 de marzo de 2017. Entrevista de Leslie Wolke a Ronald Shakespear, 2010. Publicada en dgcv.com.ar/sistema-de-senalizacion-de-subte-por-disenoshakespear/ Traducción al castellano, Elena Cetrari. (Consultado por última vez el 20 de abril de 2017).

7 Un desarrollo de este Plan en Fernández y Sznaider (2008). "Retornos de la gráfica vanguardista en un plan visual urbano". Revista Figuraciones. Teoría y crítica de artes. $N^{\circ}$ 4. ISSN: 1852-432X. Semestral revistafiguraciones.com. ar/numeroactual/articulo.php?ida=74\&idn=4\&arch=1\#texto 
Figura 1. Estación de Subterráneos

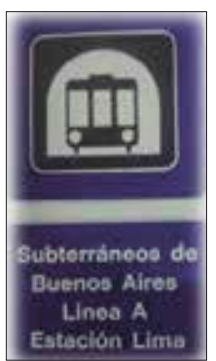

Fuente: Sistema de Señales Urbanas. Municipalidad de la Ciudad de Buenos Aires (1972) ${ }^{8}$
Figura 2. Mapa de la Red de Subtes de Buenos Aires (2015)

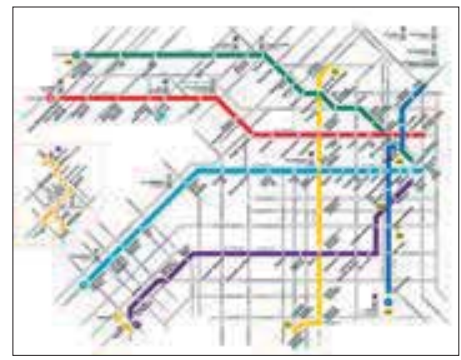

Fuente: www.metrovias.com.ar

En la primera etapa de los años'90 se trabajó en la señalización interior y en el rediseño del mapa del sistema. En el caso del mapa, basado en el del subte de Londres del año 1933, se pasó de una concepción topológica realista, asociada a una forma tradicional de comunicar los trayectos en el espacio de la ciudad, a una abstracción geométrica horizontal, lineal y angular, de gran pregnancia y legibilidad. En la superposición de trazas de trenes y calles, el uso del color y grosor de las líneas jerarquiza los recorridos del subte a partir de un efecto de plano nadir", en el que se inviertela relación "arriba-abajo" y el espacio dela ciudad es concebido desde el punto de vista y como efecto de la presencia del subte.

También queda plasmado gráficamente un diseño de red abierta, con capacidad de expandirse pero de poca redundancia o enlace a partir de sus tres rutas paralelas (líneas "B" " "D"; "A" y E" y H" y C") y, por lo tanto, con trayectos irregularmente conectados. El mapa, además, aparece deslocalizado, con una sustracción, como señala Rascovan $(2015)^{\mathbf{1 0}}$, respecto de la continuidad entre la ciudad de Buenos Aires y el Gran Buenos Aires, lo que constituye la Región Metropolitana, principal sistema de ciudades del país en extensión, cantidad de habitantes y PBI.

Recién en la última década se completa la señalética del Subte. Se trata de un proceso que continúa; pero para quien transite sus estaciones en forma regular, el efecto de completud es certero. Su novedad no proviene tanto de las características gráficas, cromáticas y tipográficas, como de sus emplazamientos, su secuencialidad y su predictibilidad, en el sentido de adaptación al espacio:

Las señales, más allá de su impronta visual y su escala, deben observar una logística perfecta en el espacio. Su emplazamiento - suspendidas, autoportantes o aplicadas-es crucial. La secuencialidad es un acto cultural.Su reiteración

\footnotetext{
8 Las imágenes incluidas forman parte del archivo personal del autor y de diversas páginas y sitios en Internet, en particular www.buenosaires.gov.ar y www.enelsubte.com. Ninguna está sujeta a restricciones de derechos de uso y su presencia en este artículo es exclusivamente para fines académicos.

9 Supino o contrapicado perfecto.

10 Para una historia de los mapas del subte porteño, véase en Rascovan (2015).
} 
cíclica elabora un plan visual que la audiencia reconoce. El conjunto construye la gramática del lugar. Es un principio de orden y servicio (Shakespear, 2015).

Un recurso muy importante que va a la dialogar con el espacio de la ciudad a nivel, es que se termina de proyectar y organizar la señalética exterior, con el mismo estilo visual de los espacios internos. Se mantiene la marca SUBTE, de 1995, apócope que se utiliza en forma tradicional entre los porteños para nombrar al servicio de subterráneos en Buenos Aires y se identifican cada una de las 6 líneas y el Premetro con colores diferentes.

Los dos diseños exteriores vigentes presentan la forma de "pastilla", pero el último, de 2015, resulta más eficaz para su identificación en todos los espacios de la Red por el juego sobre la primera y la última letra del logo que funciona como un elemento dinámico y, a la vez, unificador. Además, en "clave global", añade la fórmula "Buenos Aires Ciudad", versión que se asimila a la forma gramatical en inglés de nombrar las ciudades.

Figura 3. Señalización exterior

Estación Carlos Pellegrini, Subte “B” (2013). Estación Congreso de Tucumán, Subte “D” (2015).
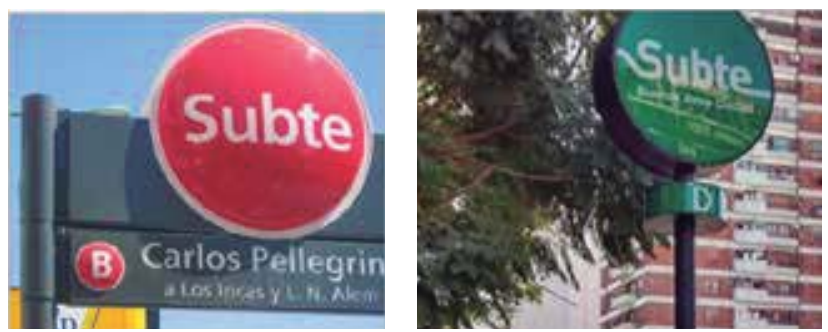

Fuente: enelsubte.com

Figura 4. Logo del Subte Vagones CAF 6000, Línea “B” (2015)

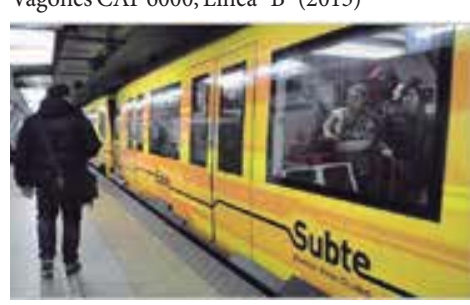

Fuente: subtedebuenosaires.blogspot.com.ar
Figura 5. Señalización exterior Comunicación institucional. Estación Av. La Plata. Línea “E” (2015)

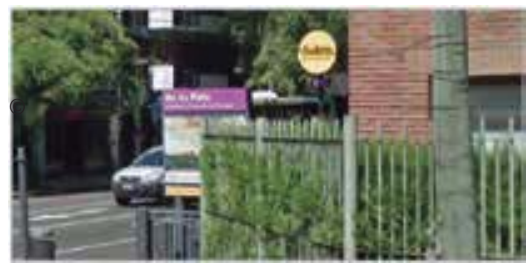

Fuente: enelsubte.com

Con la señalética exterior aparece un efecto de puntuación sobre la escena urbana por su condición suspendida. Como objeto, a la vez que se recorta del paisaje tanto diurno como nocturno - esto por la iluminación interna que le da resplandor al acrílico de doble faz—, genera una continuidad hacia adentro y hacia afuera a partir de la repetición de distintos elementos de identidad. 
Figura 6. Señalización exterior. Comunicación publicitaria. Estación Callao. Línea “D” (2016).

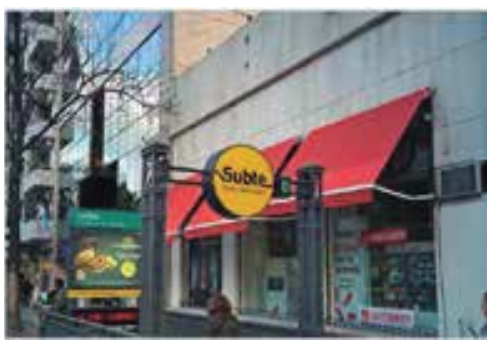

Fuente: enelsubte.com
Figura 7

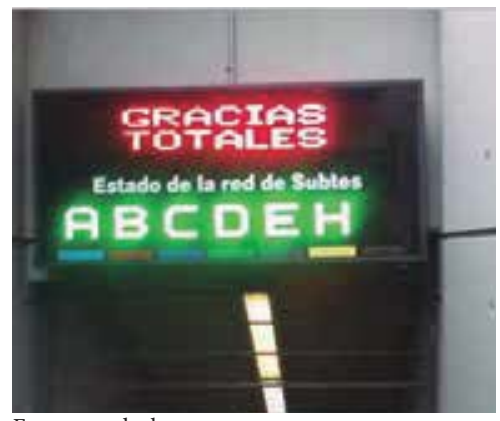

Fuente: enelsubte.com

Otro recurso comunicacional tiene que ver con la producción de mensajes que aparecen en los carteles electrónicos o "semáforos de información" ubicados en las bocas del subte y que regularmente anuncian el estado de la Red. Son frases alusivas a algún acontecimiento social; puede ser el Día del Padre: "Viejo sos lo más. Feliz Día!; o "Ni una menos" (eslogan que acompaña al colectivo de mujeres que lucha contra la violencia de género, quienes movilizaron la iniciativa ante la empresa); o "Gracias totales" (en homenaje al fallecimiento del creador de la frase y líder del grupo Soda Stereo, Gustavo Cerati).

El formato de hashtag le otorga un carácter coloquial y actual, con una empresa que se construye como cercana y sensible a las preocupaciones y sentires de la mayoría de los ciudadanos y, además, acompañando causas sociales.

Ese espacio continuo, pero marcado entre el afuera y el adentro del subte, se organiza a partir de distintas mediatizaciones. El teléfono celular, que al menos desde 2004 funciona con buena calidad de señal y cobertura en las áreas del subte porteño y en los propios vagones, consolidó la posibilidad de una comunicación interpersonal en forma ubicua en toda la ciudad; a la vez, los desarrollos del teléfono inteligente permitieron desde 2008, aproximadamente, instalar aplicaciones que ofrecen las empresas, pero también el Gobierno de la Ciudad desde su sitio www.buenosaires.gob.ar

La app oficial "BA Subte" comenzó a funcionar en 2013; brinda información actualizada del estado de toda la Red, con alertas en el caso de que haya demoras o interrupciones en una línea. Además, el Gobierno ofrece otras aplicaciones asociadas a la funcionalidad del subte y de la movilidad en general como "BA Cómo Llego", donde se pueden consultarlos recorridosparallegar a destinoyqueincluye también a colectivos y trenes. Se constituye un efecto de red de transporte que no tiene un correlato formal comosistema oplanificación queprovenga delosactores públicos y privados; allí lo que prima un sistema de competencia (colectivos que replican los recorridos de los subtes) y no de complementariedad.

El análisis del sitio web del Gobierno de la Ciudad y su lugar en el programa comunicacional de la gestión macrista requiere de un trabajo aparte (ya en 
marcha). Adelantamos, descriptivamente, que se viene consolidando desde hace varios años como un recurso de contacto hacia formas de gobierno electrónico y, en conjunto con el uso de las redes sociales por parte de organismos y funcionarios, construye un vínculo directo con los vecinos y aparece como un mecanismo de promoción de formas de participación ciudadana. Por ejemplo, para conocer la opinión respecto de la ampliación del horario del subte ya está en marcha una "consulta popular" a través de la plataforma de "Participación Ciudadana", una versión blanda, no vinculante, de las formas institucionales de democracia directa del presupuesto participativo.

Las estrategias virtuales que emplea el GCABA no excluyen los encuentros cara a cara de los principales funcionarios con los vecinos en los barrios. Convocan siempre en forma personalizada a través de folletería que entregan puerta a puerta, de llamados con mensajes grabados y directos a teléfonos de línea, con correos electrónicos y mensajes en FB. Se trata de una saturación del espacio comunicacional; de una estrategia agresiva que queda moderada desde lo estilístico por una persuasión suave, sin hiperbolizaciones, con un borramiento de la institución que enuncia y una transmutación de su condición de figuras políticas a la de vecino y par de aquellos a quienes interpelan: antes Macri y Michetti y ahora Larreta y Santilli. Una simetría construida desde el "Mauricio y Gabriela" o del "Horacio y Diego" que supone una elisión basada en la complicidad:

El debilitamiento o, directamente, la desaparición de las mediaciones partidarias e institucionales, son funcionales a esa estrategia de humanización de los dirigentes políticos que los torna, más, sujetos para ser amados u odiados, que mandatarios a quienes se les exige respuestas programáticas y soluciones racionales (Sznaider, 2015).

Figura 8. Correo electrónico personalizado del Jefe de Gobierno

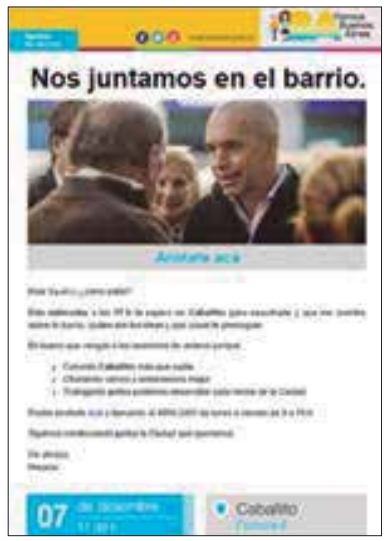

Fuente: Gobierno de la Ciudad de Buenos Aires (2016) 
Ubicados otra vez en los espacios comunes del subte, en todo las áreas de su recorrido - hasta en los baños que pese a una tradición de descuido ciudadano en los lugares públicos, en el Subte actual existen y funcionan-, encontramos marcas de ese "cinturón perpetuo", como lo llama Shakespear, que unifica los espacios de las áreas de distribución y de los andenes. Es una banda del color característico de cada estación que se engarza con zócalos o expansiones de la banda principal donde puede aparecer, por ejemplo, información orientativa o el plano de los recorridos de cada línea.

Figura 9. Señalética interior. Estación Plaza Miserere. Subte "A".

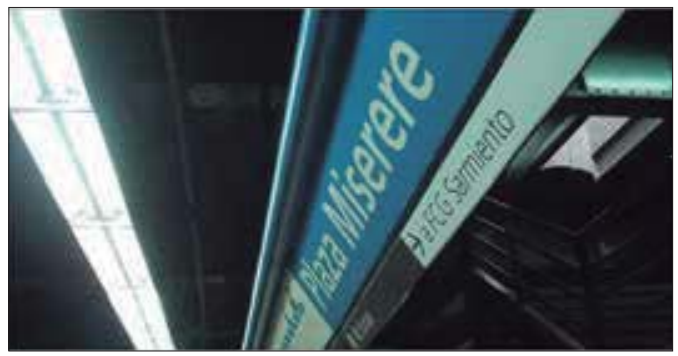

Fuente: enelsubte.com

Algunos elementos novedosos en la presentación de imágenes fijas en el espacio del Subte son las señalizaciones wayfinding en paredes y pisos, formas no estandarizadas que buscan a su propio público y que intentan aportar legibilidad y orientación al espacio físico ${ }^{11}$. También, a través de procedimientos digitales se "emiten" imágenes en pantallas led con rotación, por lo que se pasa al diseño de "programación" de imágenes fijas, en ciertos horarios y con ciertas frecuencias, un recurso de la comunicación publicitaria de empresas comerciales u organizaciones que pautan en el espacio del subte.

Figuras 10. Señalética wayfinding (2017). Estación Pueyrredón. Subte "H”.
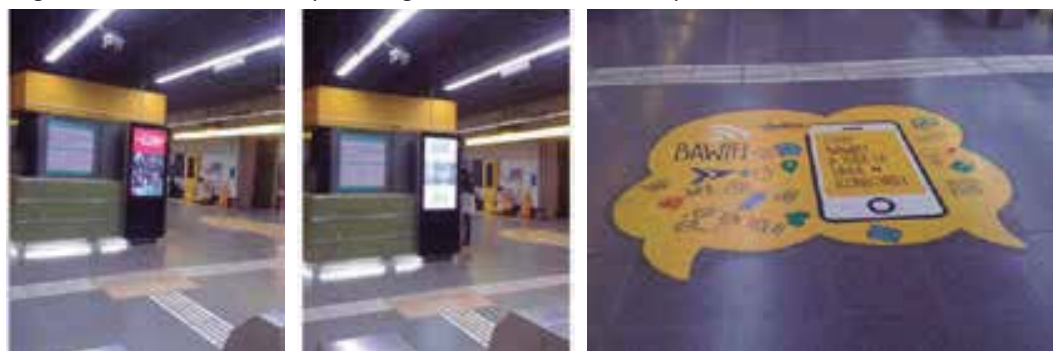

Fuente: Secuencia en tótem digital de imagen fija rotativa / Sznaider (2016)

11 El concepto se usó por primera vez en el libro La imagen de la ciudad, de Kevin Lynch (1984). Editorial Gustavo Gili: Barcelona [1960]. 
Tanto la señalización wayfinding como las pantallas led con rotación parecen trabajar a favor de una experiencia personalizada, nunca previsible, pero con una promesa de originalidad. También encontramos circuitos cerrados de TV. Se trata de una "televisión pobre", restringida por las condiciones productivas del espacio en el que emite; pero podemos pensarla como un recurso que, dentro del sistema de comunicación visual del subte, complejiza los intercambios mediatizados. La pantalla fragmentada convoca a un sujeto más usuario que espectador, atravesado por la multiplicidad, el ritmo yla extensión de la información que se difunde: datos sobre el clima, la hora, el estado de las formaciones, conviven con información institucional del Gobierno porteño, anuncios de ONGs - convocadas para que pauten gratuitamente en esos espacios del subte- y también, anuncios comerciales.

Además, desde 2015 funciona "Próximo Subte", que informa sobre el tiempo de llegada de las formaciones a la estación; por lo tanto, permite conocer sus frecuencias, lo que transparenta y objetiva aspectos relacionados a la calidad del servicio. La espera, además de las prácticas espontáneas a cargo del pasajero, queda gramaticalizada por la propia información que entrega la empresa; se establece un diálogo tácito y más allá de la calidad, la institución aparece haciéndose cargo de su tarea, como si dijese: mientras trabajo en trasladarlos en "tiempo y forma", me comunico en "forma y tiempo"12.

Figura 11. SubTV. Anuncio "Próximo Subte”. Línea “A”.

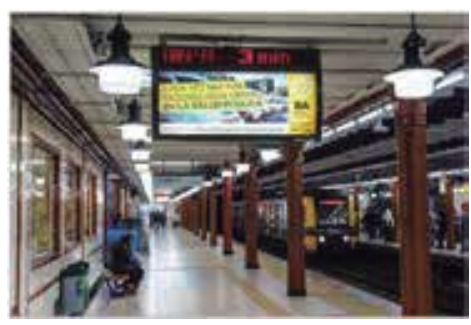

Fuente: www.buenosaires.gob.ar

Cuando hay imagen fílmica en las pantallas del SubTV, esta puede incluir o no audios en grabado. Pero también pueden existir de dispositivos sonoros de vozy musicales en vivo: la propia empresa transmite mensajes de voz en directo, típicamente, el anuncio de algún tipo de irregularidad en el funcionamiento del servicio. La presencia de músicos e, inclusive, de algún tipo de actuación teatral o de danza, funciona como un intercambio cara a cara, no mediatizado

12 Obviamente es central el dato de la calidad del servicio; pero al margen de las estadísticas concretas, consideramos que se trata de un servicio que se puede evaluar bastante satisfactoriamente por lo que la comunicación viene a modular la experiencia individual, diversa según la línea, el horario, la frecuencia y la modalidad con se viaja (transporteúnico, combinación, cercanía a las estaciones, etc.). No es que un servicio ideal deba o pueda prescindir de la comunicación, sino que intervendrán otros interpretantes. 
o una mediatización en directo, más cercana a la escena del teatro con el cuerpo modalizando esos intercambios o a las formas de la "comunicación móvil" y que se pueden considerar intercambios discursivos "híbridos":

Más allá de la conciencia de sí mismos, el sonido de los músicos compite no sólo con el ruido ambiente, sino con las emisiones radiofónicas y la música de descarga o editada por los pasajeros. El músico de subte es así, una alternativa de recepción musical entre otras (Fernández, 2015, p. 232).

Otra idea que destaca es la de los "livings" en el subte. Se trata de mobiliario que, en complemento con la conexión WIFI que ofrece en forma gratuita el Gobierno en todas las estaciones del subte desde 2016 (BA WIFI) ${ }^{\mathbf{1 3}}$, configura espacios de descanso o de espera activa. Pueden estar equipados con terminales de carga de celulares, expendedoras de bebidas y pantallas multitouch que permiten acceder a las diferentes apps oficiales de la Ciudad. Se generan ámbitos llenos, vivibles, que aportan un plus de experiencias y vuelven los recorridos "narrativizados" (Verón, 2013).

Figura 12. Espacio “Subte Digital”. Combinación de las líneas "A” y C”

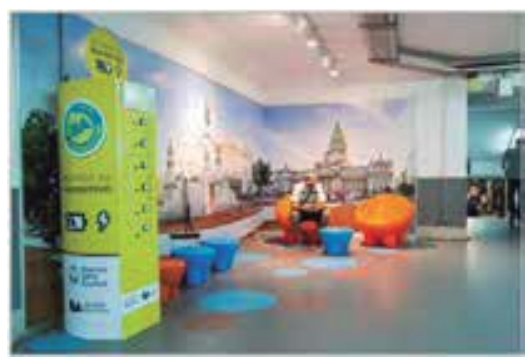

Fuente: www.buenosaires.gob.ar

A partir de la existencia de WIFI libre también se crearon cinco bibliotecas virtuales que a través del escaneo de un código QR con el dispositivo móvil, permite acceder a un catálogo de más de 200 títulos. En los últimos años también se rediseñaron los locales comerciales, se incorporaron nuevos servicios y se generaron muchos más espacios de explotación publicitaria.

Aunque describimos gran parte de la comunicación visual instalada durante los últimos años, nos quedan otros formatos como las gigantografías, las islas de descanso en los andenes o la comunicación entre vías que sólo dejamos mencionados. Quizás uno de los aspectos más paradójicos de la comunicación visual en el Subte tenga que ver con las intervenciones que tienen lugar en las estaciones más antiguas (por otra parte, la mayoría de

13 La Red WIFI de acceso público y gratuito del GCBA brinda conexión segura en casi 400 puntos dela ciudad. Además del subte incluye plazas, paradas del Metrobus y edificios públicos. Consultado el 15 de abril de 2017. En línea: buenosaires.gob.ar 
ellas). En este caso no se parte de un "lienzo en blanco"; tienen que modificar, completar o complementar la comunicación en ámbitos donde se superponen dos espacialidades, pero también dos temporalidades: entre lo que estuvo y sigue estando y lo que quiere estar. Así aparecen añadidos, yuxtaposiciones, fragmentaciones, como una especie de espacio-tiempo en conflicto, asociado al carácter expansivo de la comunicación de gobierno macrista que tiende a atiborrar todos los ámbitos.

Figura 13. Señalética y comunicación publicitaria.

Estaciones Belgrano, San Juan y Av. La Plata. Línea “E”
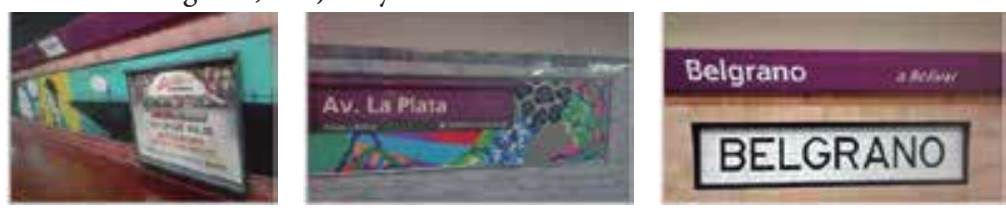

Fuente: Sznaider (2016)

Algunas observaciones complementarias: como una acción de la Legislatura de la Ciudad -que desde hace más de una década cuenta con mayoría del oficialismo-, se vienen modificando en los últimos tres años los nombres de distintas estaciones. Más allá de las polémicas frente a hechos o figuras conflictivas de la vida nacional, se alcanzó una especie de solución salomónica: se mantiene el nombre original de la estación como una manera de preservar la memoria social que guardan las denominaciones y se complementa con alguna referencia asociada a la geografía de la zona. Otras veces se impone el nombre de alguna personalidad vinculada al lugar; se trata de un tipo de iniciativa que en el estado de la opinión pública porteña actual, aparece como de bajo riesgo y costo (político y económico). Pero que como estrategia comunicacional, le permite al gobierno articular con intereses de grupos de opinión de cierta influencia en la vida de la ciudad.

Figura 14. Homenaje al fundador de la CHA (Comunidad Homosexual Argentina). Estación Santa Fe-Carlos Jáuregui. Línea “D”

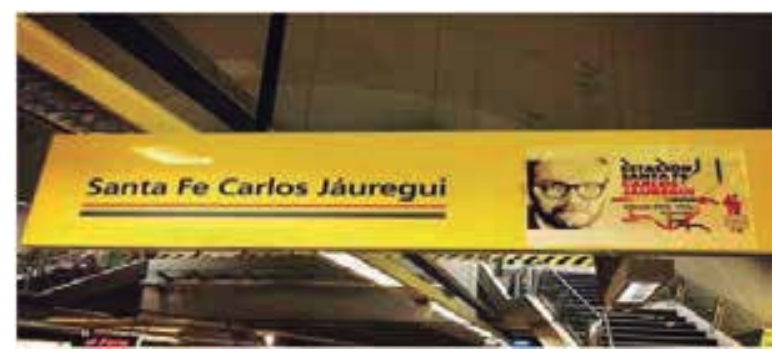

Fuente: enelsubte.com 


\section{EL ARTE MURAL}

Periodizamos tres momentos principales en la producción de arte muralen el subte de Buenos Aires, que vinculamos al carácter integral y sistemático delas intervenciones que se produjeron: el primero va de mediados de los años $30 \mathrm{a}$ mediados de los 40 y coincide con la etapa en la que quedó plasmada la Red de subterráneos sobre cuyo modelo se asientan las bases de la actual. El segundo abarca toda la década del 90 y se extiende hasta 2007. El último período se inicia en 2008 hasta la actualidad. En 1959 y 1960 y en 1969 se generaron algunas obras importantes pero puntuales y también existieron algunas iniciativas en el retorno de la democracia, en 1983 y 1984. ¿Cuáles son los cambios más importantes que se producen entre los tres períodos? En los años ' 30 dominan los paisajes de las grandes ciudades de España y las referencias a la cultura morisca; el camino de la Conquista; la evangelización; la independencia; la inmigración; estampas de la historia argentina y de su paisajes naturaleza; el mundo productivo y moderno, bajo el tópico dela riqueza material del campoy del puerto y de la transformación de la ciudad. No somos novedosos si decimos que lo que se debilitó hacia adelante son las narrativas nacionales, pensadas como resultado de operaciones discursivas que generaron los Estados-Nación y todas lasinstituciones colaborativas para construir lasidentidades nacionales y dar coherencia al proyecto moderno.

En el extremo del siglo va a prevalecer otra mirada sobre la obra de arte, sobre el arte mismo y sus espacios de exhibición que "ya no tiene(n) que ser de un modo en especial” (Danto, 1997, p. 69). De la unidad estilística que organizó el primer momento, a partir de los años 90 se pasa a una multiplicación de géneros y de estilos artísticos: aparece el homenaje al cómic, a los artistas populares, a la vida urbana y el impacto de las incipientes formas de street art en las calles de la ciudad baja al subterráneo. La llegada de la empresa privada a la concesión del subte vehiculizó algunos cambios que ya se manifestaban en la sociedad: los resumimos, por una lado, con lo que Wortman (2009) denominó "la espacialización de los consumos culturales", que supone el consumo cultural como parte de un consumo general y cuyo efecto más directo es la emergencia del marketing cultural; por otro lado, en consonancia con el fuerte proceso privatizador que vivió la Argentina en los '90, surgen las políticas de RSE (Responsabilidad Social Empresaria) y las estrategias de construcción de la reputación corporativa.

Es en ese trance que las políticas de recuperación y expansión del programa de murales en el Subte se convierten en un recurso de la comunicación institucional. Esa novedad se mantiene y amplifica hasta nuestros días cuando, además, se genera un cambio de escala en la cantidad de intervenciones muralísticas.

En los últimos años no se dejaron de realizar murales con materiales y técnicas tradicionales; no desapareció la cerámica horneada, el "trencadí" o 
mosaiquismo de cerámica partida, a la manera de Gaudío el relieve escultórico con pintura (Montes, 2002). Pero lo que interesa observar respecto de la materialidad del arte mural y desde la noción de dispositivo técnico, es la condición de permanencia y adaptabilidad de los distintos materiales a la manipulación y fijación sobre las superficies. Por eso, tenemos en cuenta que texturas, brillo, resistencia, porosidad o tensión, pueden funcionar como "cualisigno", en términos de Peirce ${ }^{14}$.

Se introducen nuevas formas de producción y nuevas técnicas artísticas. Se pasa de materiales y técnicas más permanentes a otras más perennes y de emplazamientos fijos a no fijos; se utiliza la pintura acrílica, el collage, el fileteado, la pintura en vino, la fotografía, el arte textil, las instalaciones. Todo mixturado en las distintas estaciones, pero también dentro de cada estación y generando conexiones particulares con el espacio físico. En la última década es que comienzan a aparecer con más peso estructuras no fijas: superficies rígidas de metal o madera, a su vez adheridas a la pared; o montajes sobre bastidores que permiten emplear técnicas de impresión gráfica y fotográfica sobre vinilo adhesivo. Inclusive, también aparecen impresiones directamente colocadas sobre los muros.

Figura 15. Homenaje al pintor y muralista argentino Benito Quinquela Martín. Estación Río de Janeiro, Subte "A" (2014).

Técnica: impresión sobre vinilo adherida a los nichos de la pared.

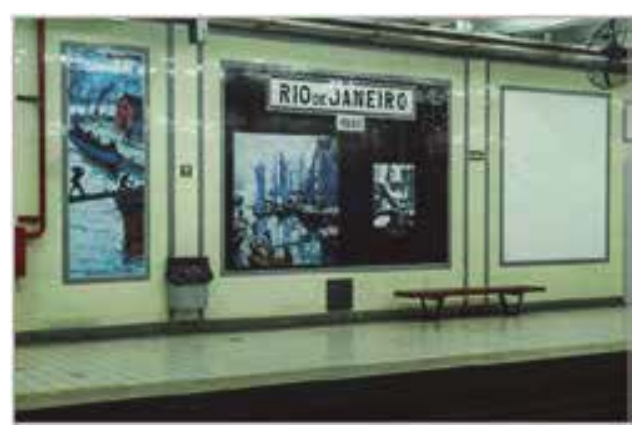

Fuente: Sznaider (2016)

Se puede pensar que predomina un criterio económico: la diferencia que va del mosaico de venecita al plotteo sobre vinilo, al modo de las esculturas que el Gobierno de la Ciudad colocó en los últimos años en el microcentro porteño, hechas en fibra de vidrio y resina epoxi en lugar de bronce, para homenajear a ídolos populares. Este "arte modesto" parece eficaz, en el sentido de su capacidad de adaptación al entorno, de generación de ambientes, de valor exhibido y ornamental. Y en el caso de algunas de las intervenciones, se generan nuevas

14 La observación fue generada para las publicaciones impresas por Valdettaro (2005, pp. 101-102). 
ritualidades, comolas selfies junto al personaje de Mafalda (combinación entre Líneas “A” y "D”) o de Messi (Estación José Hernández, Línea “D”).

Otra novedad de la última década es que por el crecimiento en la cantidad y tamaño de los murales se comenzaron a cubrir espacios no convencionales $(\dot{i} 0$ es al revés?). Por ejemplo, en los techos abovedados, en tímpano, en vestíbulos y pasillos -a nivel de los ojos-, en los laterales de las escaleras, todos creando modospropios dearticulación "contra natura", entre el tiempoyelespacio del sujeto, y el tiempo y el espacio que modela el dispositivo, como señala Aumont (1992).

Figura 16. Murales en tímpano.

Estación San José de Flores. Línea "A" y Estación Echeverría. Línea "B”.
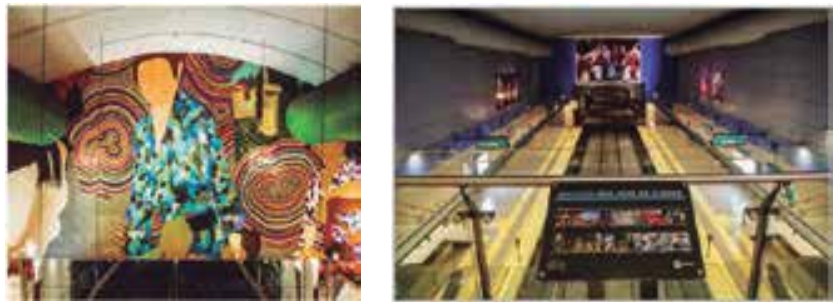

Fuente: Arte en el Subte (2016). www.buenosaires.gob.ar

Se intervienen las columnas y capiteles de andenes y de áreas de distribución. En el caso delas columnas delos andenes, el trabajo se aprecia mejor desde el interior de las formaciones donde el degradé genera efecto de movimiento, que desafía al de los vagones mismos y que cita al arte cinético.

Figura 17. Transformación de las columnas en la Estación Uruguay. Subte "B" (2015)

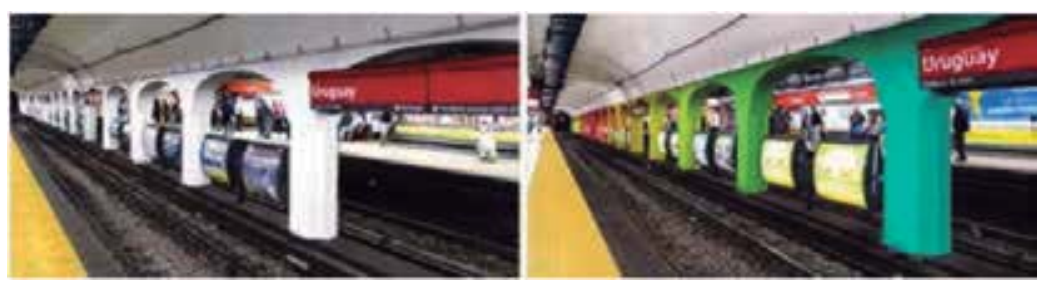

Fuente: www.buenosaires.gob.ar

Como un ejemplo entre muchos, en la Estación Plaza Italia que se corresponde con los paseos del Zoológico y del Botánico porteño, la pintura abarca también los techos y se continúa en los pasillos, lo que genera una especie de cobertura que funciona como investidura: una atmósfera lúdica, vibrante, alegre, que equilibra las tensiones propias del espacio urbano externo. 
Figura 18. Estación Plaza Italia. Línea "D”
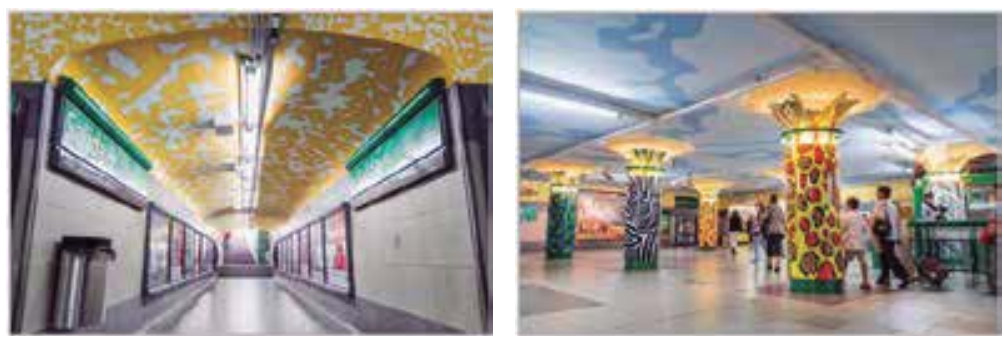

Fuente: www.buenosaires.gob.ar

En la actualidad se trabaja en un mural multisensorial en la estación Primera Junta de la Línea "A", donde se tematizan conceptos sobre el "amor fraternal" y la "educación inclusiva", pero cuya novedad tiene que con que contará con perfumes y texturas diversas.

La cantidad y calidad de artistas plásticos e ilustradores convocados es muy destacable. Mencionamos a algunos: Antonio Seguí, Jacques Bedel, Carlos Nine, Marta Minujin, Rogelio Polesello, Ricardo Carpani, Sábat. Se realizaron reproducciones de muchas obras del arte académico y del arte popular, pero también se generaron muchos proyectos originales, generalmente a cargo de artistas emergentes y de colectivos asociados al Street Art (Grupo Fase, Martín Ron, BA Street Art, Milo Lockett, entre otros).

Muchas de las intervenciones de esos artistas tienen un concepto integral que las vincula con el entorno barrial. No es original porque proviene de los años ' 90 , pero en el último período se expandió a través de distintos procedimientos: asociado al nombre de la estación o a alguna referencia cultural o social ligada al barrio; o incluso a una relación del artista participante con ese barrio, como el caso de Guillermo Roux, vecino de Flores (Estación San José de Flores, Línea "A"). Además se realizaron murales en homenaje a grandes figuras del tango a lo largo de ocho estaciones de la Línea "H", bajo la lógica del paseo cultural; una orientación que más allá de las intenciones y de los resultados, busca generar nuevos espacios simbólicos para la ciudad. También existen muchas intervenciones ad hoc, sin relación (al menos evidente) entre los motivos murales y su lugar geográfico de emplazamiento; como una acción motivada por el puro hecho y "derecho" al disfrute.

Al tratar de dilucidar el carácter temático de las intervenciones en algunas estaciones encontramos que, entre el conjunto, aparece un núcleo importante que da cuenta de temas políticos y sociales al menos sensibles para una parte importante de la población. Por ejemplo: el "Homenaje a Paco Urondo", poeta y militante de una organización armada, asesinado durantela última dictadura militar en la Argentina (Estación Puán, Línea “A”, 2008); homenaje a los Pueblos Originarios (Estación Ángel Gallardo, Línea “B”, 2014); homenaje a las huelgas 
sindicales de la Patagonia rebelde y de los talleres Vasena (Estación Medalla Milagrosa, Línea "A”, 2014); “Construyendo una sociedad igualitaria” sobre la igualdad de género (Estación Bolívar, Línea “A”, 2015); la ya descripta Estación Santa Fe-Carlos Jáuregui o el homenaje a las víctimas del atentado terrorista a la AMIA (Estación Pasteur-AMIA, Línea “B”, 2015).

Figura 19. Homenaje a las víctimas del atentado a la AMIA. Estación Pasteur-Amia. Línea "B” (2015).

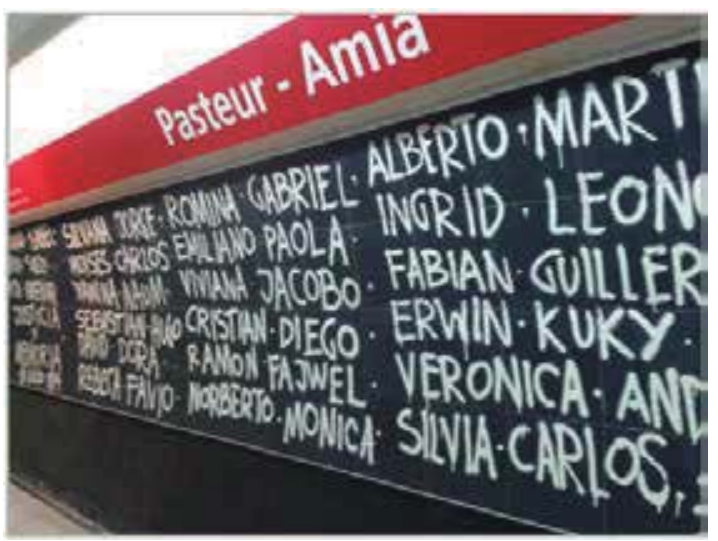

Fuente: enelsubte.com

Si por configuración espacial el de la Estación Pasteur-AMIA es un “espacio de memoria”, la Estación Once-30 de Diciembre puede ser descripta como una verdadera "estación-santuario". Inaugurada en 2007, en 2015 se le agrega el nombre "30 de diciembre", fecha en la que murieron 194 personas por asfixia en lo que se dio en llamar "la tragedia del boliche Cromañón", en 2004.

El ámbito de la estación en doble altura, la pulcritud, la iluminación tenue y focalizada sobre las distintas producciones de homenaje que incluyen fotografía, pintura, técnicas de esténcil, cubren delicadamente todos los espacios, incluidas las contrahuellas ${ }^{15}$ de las escaleras de piedra que contienen las frases: "miles de razones"; “4500 sobrevivientes"; "194 ausencias".

La referencia al motivo de las zapatillas que identifica a las víctimas adolescentes contribuye al clima de tributo ${ }^{16}$. Quizás, una respuesta destemporizada a las palabras del cardenal Jorge Bergoglio, arzobispo de Buenos Aires en 2005 (hoy, el Papa Francisco): "Buenos Aires necesita llorar. No ha llorado lo suficiente esta bofetada".

15 La parte perpendicular de donde apoyamos los pies cuando subimos o bajamos.

16 Loshechos de Cromañón reenvían a un episodio traumático para la sociedad argentina, en general, y parala ciudad de Buenos Aires, en particular. Como toda tragedia urbana, reveló carencias profundas en las acciones de control institucional y de mitigación, preparación, respuesta y recuperación del desastre por parte del Estado porteño; también quedó expuesto que fue la consecuencia de una forma generalizada de las relaciones sociales que pone a los jóvenes en el límite de la "precariedad", la inestabilidad y la incertidumbre (Svampa, 2008). 
Figura 20. Friso en esténcil, pared lateral de escalera mecánica. Estación Once-30 de Diciembre. Línea “H” (2016).

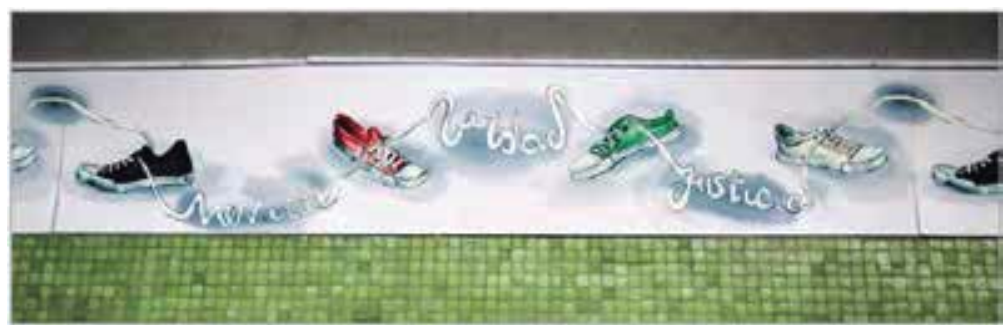

Fuente: www.buenosaires.gob.ar

El vínculo entre pasado y presente reverbera también en la reivindicación dememoria-verdad-justicia que "escriben"los cordones delas zapatillas. Si por un lado cada uno de los términos liga con valores democráticos universales, por el otro, como sintagma, en la Argentina reenvía indubitablemente a las luchas por los derechos humanos contra el terrorismo de Estado de los 70-80; una lucha que no es simbólica sino concreta por el carácter permanente de los delitos cometidos y su continuidad en el tiempo, ante la existencia de miles de desaparecidos de quienes no se conoce su destino final y de cientos de bebés apropiados y privados de su identidad. El deslizamiento entre causas, ambas ominosas pero no equiparables por su origen como por su escala y resolución, puede ser interpretado como una operación discursiva a favor de reinterpretaciones de la historia reciente y de pujas por su sentido.

Es el impacto del arte mural que no puede ser otras cosa que arte público, en tanto se incluye dentro del "conjunto de las intervenciones estéticas que actúan sobre el territorio y desencadenan mecanismos sociales e individuales de apropiación del espacio que contribuyen a co-producir el sentido del lugar" (Duque, 2011, p. 75).

\section{CONCLUSIONES}

La comunicación de gobierno local tematiza siempre algún tipo de vínculo entre gobierno, población y espacio urbano. ¿Cuáles novedades surgen a partir de la expansión de las formas de intervención artística y comunicacional en los espacios del subte de Buenos Aires durante la última década? El GCABA construye una continuidad que se inscribe en una tradición más larga al desarrollar el sistema del arte mural en el Subte; pero lo hace a través de formas propias que articulan con el estilo general de la época, desde lo ecléctico y lo multirreferencial. La comunicación institucional toma el mismo camino, ampliando y completando las intervenciones generadas a partir de $1995 \mathrm{y}$ con antecedentes en 1972. Como impresión total, se genera un efecto de espacio muy trabajado. 
La comunicación institucional en las bocas de subte funciona como una interfaz entre la ciudad a cielo abierto y la ciudad subterránea, en el sentido de una zona de comunicación de un sistema sobre otro que homogeniza e identifica y que articula con la profusa comunicación de gobierno en vía pública y con su comunicación en medios masivos y en Internet, en general. Los espacios internos dejaron de ser ámbitos despojados y/o desatendidos para convertirse mayormente en entornos amigables, con una expansión delugares de consumo y servicios y de ámbitos de recreación que también construyen continuidad y funcionan como prolongaciones entre el afuera y el adentro, igual que las formas del street art en el subte.

Además, el arte urbano o callejero atravesó en la última década un doble movimiento que va de una institucionalización - sobre la que no importa aquí considerar sus implicancias-a una apropiación como práctica privada, en la que muchos vecinos optaron por realizar murales en los frentes de sus viviendas. Pensamos este movimiento como un intento práctico y bastante exitoso de evitar su afectación a través de grafitis, tags, pintadas o cartelería política; pero sobre todo, creemos que se trata de procedimientos que recortan el espacio intervenido respecto de entornos uniformes, como gesto de individuación y de apropiación creativa del espacio público, lo que se verifica en la tendencia de incluir murales en medianeras internas de terrazas de casas y edificios. En sintonía, el GCABA generó en los últimos años acciones sistemáticas de recuperación de fachadas de viviendas particulares que describe como "vandalizadas", en un movimiento si se quiere doméstico que responde a la "teoría de la ventana rota"17.

Se trata de coincidencias no estridentes pero que suponen una simetrización entre los modos de acción del gobierno y de participación de algunos segmentos de la sociedad; esas acciones con sesgos comunes, se orientan a la producción de un espacio urbano controlado, con estrategias donde lo protectivo (sobre los muros, pero que se puede proyectar sobre los bienes y, por qué no, sobre los cuerpos) cobra un valor configurante del vínculo entre gobierno, vecino y espacio urbano.

Aunquela comunicación del gobierno en los espacios del subte opera sobre una superficie acotada respecto de las posibilidades de comunicación en la vía pública, se replican las superposiciones, las redundancias, los desbalances propios de la comunicación en toda gran ciudad: desequilibrios de inversión y de mantenimiento, disparidades en el desarrollo de la señalética en las distintas líneas, descuido en el tratamiento del patrimonio cultural, cartelería comercial ubicada sobre los murales, señalética institucional que compite con las formas artísticas, saturación visual, etc.

17 Es una teoría sociológica y criminológica desarrollada por George L. Kelling entre los años ‘ 80 y ‘ 90 , que afirma que en entornos urbanos cuidados puede haber una disminución del vandalismo y de hechos delictuales y que quedó asociada a las políticas de "tolerancia cero". En Fernández Quesada, B. \& Lorente, J. P. (2009). 
En ese sentido, el esfuerzo del Gobierno de la Ciudad por homogeneizar los espacios del subte como ámbito de comunicación de su identidad, encuentra límites que provienen de sus propias estrategias, pero que también son estructurales y que vienen del pasado porque debe trabajar a partir de lo que recibió; inclusive respecto de la comunicación visual no todo puede ser reemplazado y en el caso de los murales, nada debería ser reemplazado.

La institución que enuncia lo hace desde un lugar omnipresente, pero no expuesto; eficiente, pero no ostensible; los espacios del subte, como ya señalamos, se presentan como terminados, como con "final de obra" y desde ese lugar, la institución se dispone como un "anfitrión” que dejó todo listo y se retira para que disfruten los "invitados", además de que puede y quiere ser sometido al juicio del otro. Por eso decimos que el espacio construido es festivo, lleno, vivo, ideal, respecto de las conflictividades propias del espacio urbano. En ese sentido, la comunicación del GCABA configura un espacio social mixtópico, como ese espacio donde se materializan proyectos utópicos sólo y a partir de la existencia de distintas discursividades y mediatizaciones posibles (Traversa, 1994).

Se convoca a un ámbito a la vez ordenado y prolijo, pero también armonioso, experiencial y estimulante. En su modo de implicar los espacios comunes del subte propone un confort tangible, algo lujoso para la idiosincrasia o para lo probado por los porteños. En lo funcional sumamos la inclusión de aire acondicionado y de aromatización de los vagones de subte, la posibilidad de poder viajar con mascotas y, en breve, con bicicletas.

A ese espacio hipercomunicado le corresponde un sujeto a la vez usuario y espectador. Un sujeto "hidra" no monstruoso ni con aliento venenoso, pero sí expuesto a múltiples estímulos visuales y sonoros; distinto al público de la prensa, del cine y de la televisión, pero parecido al de las redes sociales. Porque por un lado es requerido desde múltiples dispositivos a partir de una oferta que lo excede y que le exige la atención espectatorial del broadcasting para buscar una información, para disfrutar de un músico o de un mural; por el otro, se manifiesta la condición más horizontal, inmediata e interactiva del networking porque ingresa al subte utilizando distintas aplicaciones en su celular sobre las que además opina y opina también sobre el servicio del Subte; porque recibe información desde múltiples pantallas en las que conviven distintas temporalidades; porque aparece lo multimedia y también lo transmedia. Hablamos de lo espectatorial y de lo interactivo conviviendo, como nuevas formas de las mediatizaciones que se podrían definir como social-multitasking (Fernández, 2016b).

Las novedades artísticas y comunicacionales introducidas por el Gobierno de la Ciudad en el espacio del subte porteño desde hace más de una década le hablan a un individuo de la época y a un sujeto en plataforma. Y al jerarquizar un vínculo cercano y cómplice, le permite sostener una idea de gobernabilidad 
a escala local, cuasi vecinalista, que por un lado da respuesta a demandas básicas de mantenimiento, administración, regulación y control de la infraestructura básica de uso público del territorio y a la gran performance de los sujetos en la vida urbana, como es la movilidad. Pero por el otro lado, tiende a velar el debate sobre temas estratégicos (ciudad productiva, ciudad inteligente, modelos de educación y de seguridad, políticas ambientales, DD.HH. de nueva generación, etc.), temas que exponen conflictos de intereses profundos con distintos actores sociales ${ }^{\mathbf{1 8}}$.

Aparece una vocación del gobierno de intervenir en los debates públicos desde un repertorio argumentativo no confrontativo y no segmentado, que articula con una ciudadanía que elige cómo participar, pero que prefiere encuadrarse en una cultura de lo individual. Un estilo que parece explicar mucho acerca de los apoyos de gran parte de la población a la gestión del PRO en la ciudad de Buenos Aires y que marca la necesidad de seguir pensando las incertidumbres políticas y sociales en épocas de complejidades mediáticas y nuevas mediatizaciones, para elevar el nivel de imaginación y de demanda social.

18 Alplantear esa sustracción, tenemos en cuenta quela ciudad de Buenos Aires aportala cuarta parte del PBInacional y contiene a un $7 \%$ de la población total del país; y aunque la perspectiva municipalista es necesaria, debería ser tributaria de un proyecto integral sobre la ciudad y no un recurso excluyente. 


\section{REFERENCIAS}

Amar, G. (2011) Homo mobilis. La nueva era de la movilidad. Buenos Aires: La Crujía.

Augé, M. (1998). El viaje subterráneo: un etnólogo en el metro. Barcelona: Gedisa.

Augé, M. (2010). El metro revisitado: El viajero subterráneo veinte años después. Madrid: Paidós.

Aumont, J. (1992). La imagen. Barcelona, España: Paidós.

Barthes, R. (1987). El estilo y su imagen. El susurro del lenguaje. Barcelona: Paidós.

Barthes. R.(1993).Semiología yurbanismo. La aventura semiológica. Barcelona: Paidós.

Belej, C. (2012). El arte mural de las estaciones de trenes subterráneos de Buenos Aires en la década de 1930. Intersticios. Revista Sociológica de Pensamiento Crítico, vol. 6, (I), pp. 257-268. En línea: http://www.intersticios.es/article/view/9804/6799

Danto, A. (1997). Más allá de la caja Brillo. Madrid: Akal.

Duque, Félix (2011). Arte urbano y espacio público. Res Pública. Revista de Historia de las Ideas Políticas, $\mathrm{N}^{\circ} 26$, pp. 75-93. En línea: http://www.revistas.ucm.es/index. $\mathrm{php} / \mathrm{RPUB} / \mathrm{article} / \mathrm{view} / 47834 / 0$

Fernández, J. L. (2008). La construcción de lo radiofónico (director). Buenos Aires: La Crujía.

Fernández J. L. (2012). La captura de la audiencia radiofónica. Buenos Aires: Líber Editores.

Fernández, J. L. (segundo semestre 2015). Música, músicas y redes en el espacio urbano. En revista L.I.S. Letra. Imagen. Sonido. Ciudad Mediatizada, año VII, No 14, pp. 219-234. En línea: http://www.revistalis.com.ar/index.php/lis/article/view/205

Fernández, J. L. (2016a). Auriculares para pensar. En revista electrónica Anfibia. Universidad Nacional de San Martín (UNSAM). En línea: revistaanfibia.com/ ensayo/auriculares- para-pensar/

Fernández,J.L.(2016b).Interacción: un campodedesempeñomúltipleen broadcastingy en networking. En G.CingolaniyB.Sznaider,B.(editores). Nuevasmediatizaciones nuevos públicos cambios en las prácticas sociales a partir de las transformaciones del arteylosmediosen la red (pp.10-26). Centro de Investigaciones en Mediatizaciones (CIM): Universidad Nacional de Rosario(UNR), Argentina. En línea: http://www. cim.unr.edu.ar/archivos/cuadernodelcim_4_nuevas_mediatizaciones_nuevos_ publicos.pdf

FernándezQuesada, B. \&Lorente,J.P. (editores) (2009).Arteenelespaciopúblico:barrios artísticos y revitalización urbana. Zaragoza: Prensas Universitarias de Zaragoza.

Goffman, I. (1991). Los momentos y sus hombres. Barcelona: Paidós. 
Igarza, R. (2009). Burbujas de ocio. Nuevas formas de consumo cultural. Buenos Aires: La Crujía.

Montes, C. (2002). Dalí y Gaudí: genios y monstruos. Barcelona: Loft Publicaciones.

Rascovan, A. (segundo semestre 2015). Desintegración y sustracción. La ciudad de Buenos Aires a través de los mapas del subte. En revista L.I.S. Letra. Imagen. Sonido. Ciudad Mediatizada, año VII, No 14, pp. 111-130. En línea: http://www. revistalis. com.ar/index.php/lis/article/view/198/246

Shakespear, R. (2005). Haciendo la ciudad legible. En Blog Ronald Shakespear En línea: http://www. ronald shakespear.com/2015/01/haciendo-la-ciudad-legible/

Steimberg, O. (2013). Semióticas. Las semióticas de los géneros, de los estilos, de la transposición. Buenos Aires: Eterna Cadencia.

Svampa, M. (2008). Pensar Cromañón, entre el hecho y el movimiento. En Cambio de época: movimientos sociales y poder político. Buenos Aires: Siglo XXI.

Sznaider, B. (segundo semestre 2013). Relaciones entre marketing territorial y marcaciudad. En revista L.I.S. Letra. Imagen. Sonido. Ciudad Mediatizada, año IV, No 10, pp. 55-77. En línea: http://www. revistalis.com.ar/index.php/lis/article/view/137

Sznaider, B. (mayo 2015). De las ciencias sociales, del fenómeno macrista, de la comunicación y de otras yerbas... En revista Sociales, $\mathrm{N}^{\circ} 87$, pp. 80-85. En línea: http://www. sociales.uba.ar/wpcontent/uploads/15.-SOCIALES-87-DSZNAIDER.pdf

Traversa, O. (1994). Las mixtopías. Las utopías mediáticas. En V. Fortunati, O. Steimberg y L. Volta (compiladores). Utopías. Buenos Aires: Corregidor.

Valdettaro, S. (2005). Prensa y Temporalidad. En revista La Trama de la Comunicación, Vol. 10, Rosario: UNR Editores, pp. 92-102. En línea: http://www.latrama.fcpolit. unr.edu.ar/index.php/trama/article/view/124

Verón, E. (1983). Crise économique et crise urbaine. En Crise de L'Urbain-Futur dela ville 1, Temps Libre, Paris, Hiver, $\mathrm{N}^{\circ}$ 8, pp. 95-128. (En colaboración con Sophie Fisher).

Verón, E. (2013). El cuerpo como operador (II): relatos de viaje. La Semiosis Social 2. Ideas, Momentos, Interpretantes. Buenos Aires: Paidós.

Wortman, A. (Julio 2009). Cambios culturales, cambios en los consumos culturales. En revista Indicadores Culturales, UNTREF: Buenos Aires, pp. 100-109. En línea: http://www.untref.edu.ar/documentos/indicadores_culturales/2009/ Cambios\%20- \%20Ana\%20Wortman.pdf 


\section{IDENTIFICACIÓN DE LAAUTORA}

Beatriz Sznaider es Magister en Comunicación y Cultura por la Universidad de Buenos Aires (UBA), Argentina. Es docente en Ciencias de la Comunicación, Facultad de Ciencias Sociales de la UBA y ha dirigido y participado en diversos proyectos de investigación. Es integrante del Consejo de Redacción dela revista L.I.S. Letra. Imagen. Sonido. Ciudad Mediatizada y ha publicado artículos en publicaciones académicas y ha participado como editora y autora en libros dedicados a reflexionar sobre diversas problemáticas del campo de la comunicación y la cultura.

\section{REGISTRO BIBLIOGRÁFICO}

Sznaider, Beatriz (2017). Mediatizaciones en los subtes de Buenos Aires. Arte mural, comunicación y espacio urbano. InMediaciones de la Comunicación, 12(1), 305-331. 